\title{
Aboveground biomass estimation with airborne hyperspectral and LiDAR data in Tesinske Beskydy Mountains
}

\author{
*Olga Brovkina ${ }^{1}$, František Zemek² ${ }^{\text {, Tomáš Fabiánek }}{ }^{2}$ \\ ${ }^{1)}$ Faculty of Forestry and Wood Technology, Mendel University in Brno, Zemedelska 3, 61300, Czech Republic, \\ e-mail:brovkina.o@czechglobe.cz, \\ ${ }^{2}$ Remote Sensing Department, Global Change Research Centre, Academy of Sciences of the Czech Republic, \\ v.v.i., Brno, Belidla 986/4a, 60300, Czech Republic.
}

\begin{abstract}
Brovkina Olga, Zemek František, Fabiánek Tomáš. 2015: Aboveground biomass estimation with airborne hyperspectral and LiDAR data in Tesinske Beskydy Mountains - Beskydy, 8 (1):35-46

The study presents three models for estimation of forest aboveground biomass (AGB) for plot level using different categories of airborne data. The first and the second models estimate AGB from metrics of airborne LiDAR data. The third model estimates AGB from integration of metrics of airborne hyperspectral and LiDAR data. The results are compared with plot level biomass estimated from field measurements. The results show that the best AGB estimate is obtained from the model utilizing a fusion of hyperspectral and LiDAR metrics. Study results expand existing research on the applicability of airborne hyperspectral and LiDAR datasets for AGB assessment. It evidences the efficiency of using a predicting model based on hyperspectral and LiDAR data for study area.
\end{abstract}

Key words: forest aboveground biomass; hyperspectral data; airborne LiDAR; Beskydy Mountains.

\section{Introduction}

More information on standing forest aboveground biomass (AGB) is needed to improve our understanding of the global carbon cycle (Penner et al., 1997). AGB is an important variable for evaluating ecosystem structure and function across the landscape. Generally, traditional methods of estimating AGB use allometric equations, each developed as a function of tree species, tree height and diameter at breast height (DBH). Data collection for these methods is time-consuming, expensive and not always reliable (Labrecque S. et al., 2006). Remote sensing techniques allow us to examine ecosystem processes at multiple scales because the data these techniques provide cover a large area of interest with quite high re-visitation frequencies (Goetz et al., 2000, Running et al., 2000).
Currently, there are papers in the literature where airborne hyperspectral (HS) and airborne LiDAR are used with a wide range of methods for AGB estimation. LiDAR is considered the most accurate remote sensing technology for mapping biomass (Zolkos et al. 2013). The laser pulse returns are usually used to derive forest height metrics, which can be related to field-observed AGB (Nasset 1997, 2011; Tsui et al. 2012; Kankare et al. 2013). Some studies apply a fullwaveform properties, such as average intensity from a top-of-the-canopy level, average echo width from a top-of-the-canopy level and average number of echoes per pulse, in additional to forest height metrics for biomass estimation (Latifi et al. 2010, 2012; Heinzel \& Koch 2011).

Airborne HS data for AGB estimation are used, mostly, to analyse suitable band and vegetation indices for tree species classification 
(Buddenbaum et al. 2005), leaf area index (Dudeni et al. 2009) and forest biochemical status (Huber et al. 2008) related to biomass values. Le Marie etal. (2008) describe the set of indices used to extract information regarding the canopy leaf biomass from hyperspectral (Hyperion) data. However, the robustness of the indices in general has not been demonstrated. Schlerf (2006) state that the biomass cannot be retrieved from hyperspectral data, because there was only a poor relationship between stem biomass and vegetation indices. He recommends the use of a combination of hyperspectral and other kinds of remote sensing data for AGB estimation.

The use of multi-sensoral data for forest biomass assessment has gained interest. This is mainly due to the complementary information content of the data, like tree species type from optical data and height information from LiDAR data. Koch (2010) presents a state-of -the-art review of lasing and hyperspectral scanning for forest biomass assessment, which highlights the fusion of these two categories of airborne data. For example, a fusion of airborne hyperspectral and LiDAR data has been used in the studies of Latifi et al. (2012) and Laurin et al. (2014) for the AGB estimation in German forest stands (RMSE ranging between 38 and $48 \%$ ) and West Africa rainforests $\left(\mathrm{R}^{2}=0.70, \mathrm{RMSE}=61.7 \mathrm{t} / \mathrm{ha}\right)$, respectively. Findings of Laurin et al. (2014) showed that the integration of hyperspectral bands $\left(R^{2}=0.70\right)$ improved the model based on LiDAR data alone $\left(\mathrm{R}^{2}=0.64\right)$ for AGB estimation in tropical regions. On the contrary, LiDARbased predictions were not notably improved by contributing hyperspectral features in biomass assessment for coniferous species in a temperate forest site in Germany (Latifi et al. 2012).

However, the integration of HS and LiDAR information in forest inventories is still in experimental stage across forest stands in Central Europe. There are no publications known to authors with the development of a robust model for AGB assessment that can be applied under different natural growing conditions in forests of the Czech Republic. Previous AGB assessments in our study area involved only the use of satellite Landsat TM and SPOT data for coniferous forest stands (Main-Knorn et al. 2011, 2013).

This study aims: 1) to estimate forest AGB using airborne HS and LiDAR data for beech and spruce forest stands, and 2) to examine whether the use of HS airborne data in addition to LiDAR data can improve the AGB estimation for the study area.

\section{Materials and methods}

\section{Study area}

The study area is located in the Beskydy Mts. Protected Landscape Area, in the north-eastern part of the Czech Republic, latitude $49.50{ }^{\circ} \mathrm{N}$, longitude $18.80{ }^{\circ} \mathrm{E}$ (Fig. 1). The mountains consist of a highland, gradually sloping towards Poland and Slovakia. The altitude varies between 500 and $900 \mathrm{~m}$. The inclusion of the Beskydy Mts. in the Outer Carpathian range is reflected in their geological structure, with alternating series of claystone, sandstone and conglomerate. The soils are mostly of a sandyloam to loamy-sand texture. The dominant forest types are even-aged monocultures of Norway spruce (Picea abies) followed by European beech (Fagus sylvatica) forests and negligible shares of stands or scattered occurrence of Scots pine (Pinus sylvestris), Silver fir (Abies alba), European larch (Larix decidua) and Ash (Fraxinus excelsior) (Michalko 1986). Forests in this area are characterized by highly variable tree vigour and mortality rates due to severe air pollution during the communist times, as well as unsuitable forest management (Kozak 1996, Grodzki 2006).

\section{Data sets}

\section{Airborne data}

The hyperspectral imagery data set was acquired by AISA Eagle sensor on $27^{\text {th }}$ September, 2011, with a spatial resolution of $5 \mathrm{~m}$. There were 65 spectral bands in the spectral range of 400 to $970 \mathrm{~nm}$. The image preprocessing included radiometric, atmospheric and geometric corrections. Radiometric correction of the hyperspectral images was performed using CaliGeo 4. 6. 4 (Spacim) software and ENVI 4. 4. Atmospheric correction was done in ATCOR4 6.0 (ReSe Applications Schlaepfer) and georectification was in PARGE 3. 2.

LiDAR data were acquired during the vegetation period of 2013 using a Riegl LMSQ680i scanner, which resulted in a point cloud density 1 point per square meter. The data were preprocessed by the vendor, Czech Office for Surveying, Mapping and Cadastre (CUZK, www.geoportal.cuzk.cz). It encompassed fullwaveform decomposition and georeferencing from RiProcess software package (by Riegl) and an export in LAS format after strip adjustment. 


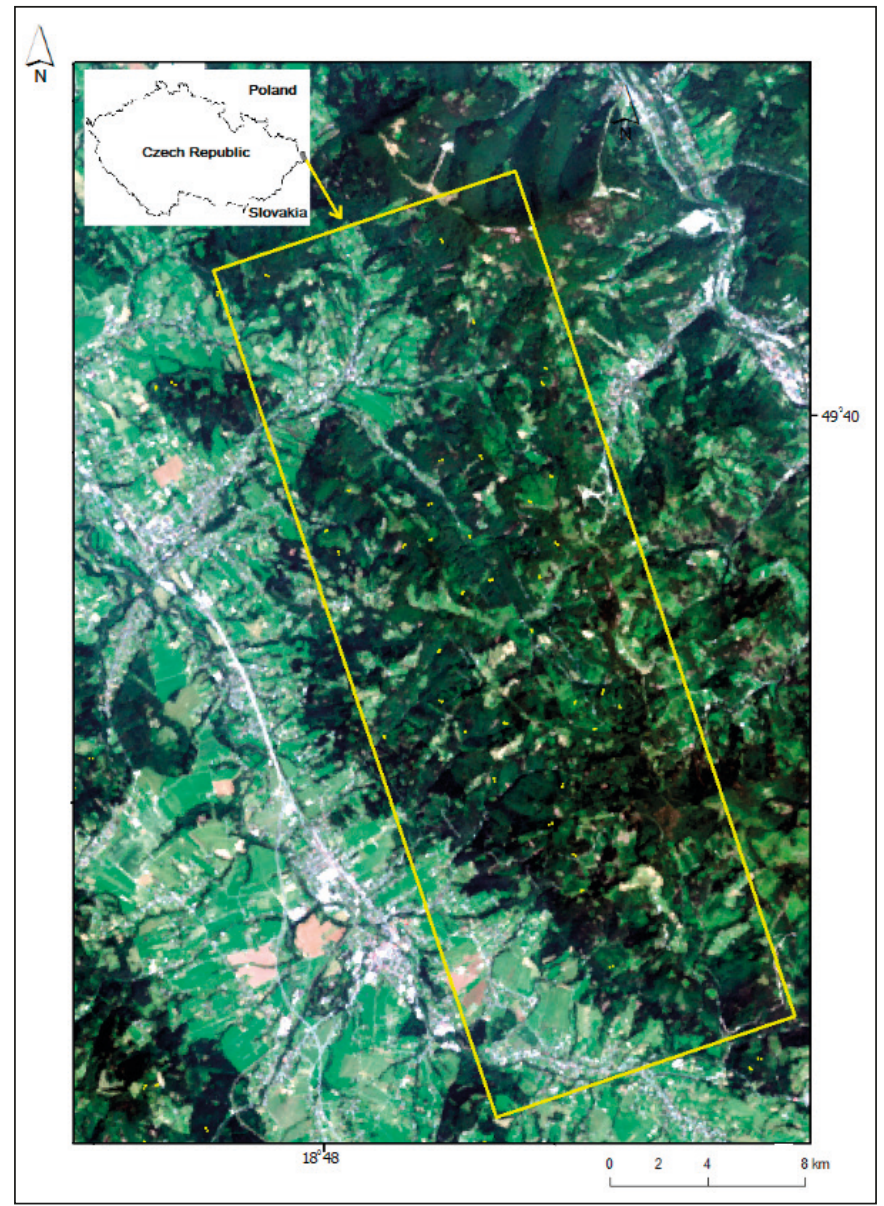

Fig. 1: Location of the study area.

\section{Field data}

Field data were collected by the Institute of Forest Ecosystem Research (www.ifer.cz) in 2013 and included an inventory of plots systematically distributed over the airborne data area, with measurements of tree height, DBH (diameter at breast height), age, species composition and crown length. These variables were measured using the Field-Map technology (www.fiedlmap.cz), including an electronic caliper for breast height measurements and laser rangemeter for tree height and tree crown attributes. We matched 56 plots from the field data with airborne data. The area of each plot was $500 \mathrm{~m}^{2}$. AGB values were calculated for plot level based on field allometry for prevailing species of Norway spruce and European beech in the study area.

\section{Methods}

We estimated AGB for tree plot level based on three models with metrics from airborne hyperspectral and LiDAR data (Fig. 2). The first and the second models included metrics from LiDAR data, the third model included the integration of metrics from HS and LiDAR data. All 56 plots were split in calibration (28 plots) and validation (28 plots) sets. Spruce 34 plots were split in calibration (17 plots) and validation (17 plots) sets. Beech 15 plots were split in calibration (7 plots) and validation (8 plots) sets. We did not consider predictors for mixed plots due to the small number of plots for splitting data in calibration and validation sets. The models were validated based on AGB for plots from field data. We describe metrics from LiDAR and hyperspectral data and each of the models further in the paper. 


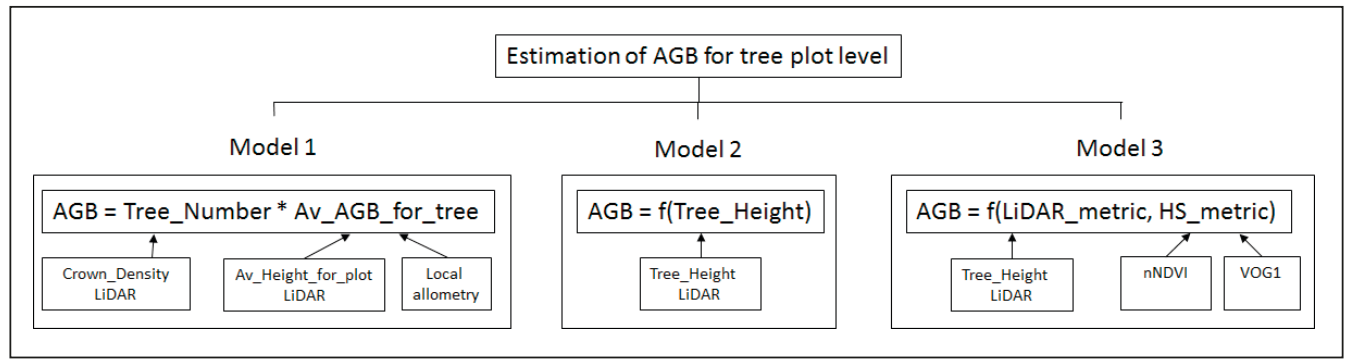

Fig. 2: Framework of estimating AGB.

\section{LiDAR metrics}

Canopy density and canopy height for tree plot level were derived from airborne LiDAR data. Canopy density, or canopy cover, is the ratio of vegetation to ground as seen from the air. Firstly, the separation of LiDAR point cloud was done to split lidar ground multipoint and aboveground points. Secondly, the division procedure of the amount of aboveground points and the amount total points was applied. The procedure given the ratio from 0.0 to 1.0, where 0.0 represented no canopy and 1.0 very dense canopy. The accuracy of LiDAR canopy density was estimated from field measurements of the number of trees for plot-level. The metric was employed for modelling of plot tree numbers in Model 1.

Canopy height measures how far above the ground the top of the canopy is. The first return points and bare earth points were generated and the difference between these two point datasets was determined. The difference results represented, over forest, the canopy height. The accuracy of LiDAR canopy height was estimated from field measurements of height of trees with plot level. The metric was employed for AGB estimation in Model 2 and Model 3.

\section{Hyperspectral metrics}

We calculated for further selection 7 hyperspectral predictors that already had a potential predicting of AGB for relatively similar to our study forest area in recent reports (Fassnacht et al. 2014, Zhang et al. 2009, Laurin et al. 2014, Thenkabail et al. 2004). There were 4 vegetation indices (VI), first component of the principal component analysis (PCA) and two narrow spectral bands $\left(\right.$ band $_{505}$ and band ${ }_{688}$ ). The VI predictors were from the association between optical data and biomass originated mostly from species information, vegetation density and leaf water content (Fassnacht et al. 2014): Normalized Difference VI (NDVI), Near Infrared Red Edge Normalized Difference VI (NDVI ${ }_{705}$ ), Vogelmann Red Edge index (VOG1) (Vogelman et al. 1993) and Water Band Index (WBI).

\section{Map of species composition}

HS data were used for creation of map of species composition. Supervised classification by Mahalanobis Distance method (Richards 1999) was applied using ENVI 5.0 software. The procedures began with formation of forest type classes for classification as regions of interest (ROI) on the image. The field data were used for ROI creation. All pixels were classified into six ROI classes: "spruce", "beech", "pine", "silver fir", "shadows" and "artificial objects" (roads and buildings). Based on a minor presence of pine and silver fir species in plots we assumed in the study that coniferous were mostly spruce. The accuracy of a classification result was estimated after classification by calculation of the confusion matrix. Hyperspectral classification results were used for AGB estimation in all models of the study to separate AGB for spruce, broadleaves and mixed species.

\section{Model 1}

$$
A G B_{\text {plot }}=\text { Number }_{\text {of trees }} \cdot A G B_{\text {tree }}
$$

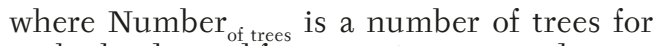
each plot derived from LiDAR canopy density metric based on the equation:

$$
\begin{aligned}
& \text { Number }_{\text {of trees }}=0.007^{*} \text { CanopyDensity }_{L i D A R}+ \\
& +0.29\left(\mathrm{R}^{2}=0.7\right) .
\end{aligned}
$$

$\mathrm{AGB}_{\text {tree }}$ is an average biomass for tree level calculated according to tree species and using the following allometric equations: 


$$
\begin{aligned}
& A G B_{\text {for spruce }}=A G B_{\text {needles }}+A G B_{\text {branches }}+ \\
& +A G B_{\text {dry branches }}+A G B_{\text {stem }}
\end{aligned}
$$

where each category was calculated as:

$$
A G B=a \cdot b \cdot \exp (c \cdot \ln (D B H)-d),
$$

(Wirth 2004)

where:

$a=1.0849, b=1.0226, c=1.9162, d=3.19632$ for AGB $_{\text {needles; }}$;

$a=1.1332, b=1.0103, c=2.2552, d=3.96201$ for

$A B_{\text {branches; }}$;

$a=1.1146, b=1.1107, c=2.04823, d=3.09062$ for

$A G B_{\text {dry branches; }}$;

$a=1.0142, b=1.0238, c=2.50602, d=2.50602$ for

$A G B_{\text {stem }}$;

$\mathrm{DBH}$ is a diameter $[\mathrm{cm}]$ at breast height of spruce trees. To retrieve DBH for spruce trees a parameterized model from IFER was used based on the measured tree height at the sample plots $\left(\mathrm{R}^{2}=0.84, \mathrm{n}=257\right)$ :

$$
D B H=-\frac{b}{\log \left(\frac{H-1.3}{a}\right)},
$$

where $a=64.188, b=30.446$.

$$
A G B_{\text {for beech }}=0.0551 \cdot \mathrm{DBH}^{2.11} \cdot \mathrm{H}^{0.589} \text {, }
$$

(Wutzler et al. 2008)

where $H$ is a mean height [m] of beech trees for the plot. To retrieve DBH for beech trees a generated model from IFER was used, Equation (2), with $\mathrm{R}^{2}=0.60$, $(\mathrm{n}=447)$, where $a=59.567$, $b=30.472$.

Based on a minor presence of maple, alder and larch in plots with broadleaved species we assumed in the study that broadleaves were mostly beech and all calculations for broadleves plots were done with allometry for beech. If plot contained one class with spruce or one class with beech species from the hyperspectral classification (Fig. 3 a, b) we calculated $A G B_{\text {plot }}$ based on corresponded allometry for species. If plot contained two classes of spruce and beech from the hyperspectral classification (Fig. $3 \mathrm{c}$ ) we calculated $A G B_{\text {plot }}$ as a weighted sum of AGB for spruce and AGB for beech. Where weights were assigned as a ratio of species area to the plot area derived from the hyperspectral image classification. The model was validated based on AGB from field measurements summing up for each plot.

\section{Model 2}

$$
A G B_{\text {plot }}=f\left(\text { TreeHeight }_{\text {LiDAR }}\right),
$$

where TreeHeight ${ }_{\text {LiDAR }}$ is an average height of trees for each plot area.

We separated the estimation of AGB for all plots, for plots with spruce trees and for plots with beech trees based on hyperspectral classification: $\mathrm{AGB}_{\text {all }}, \mathrm{AGB}_{\text {spruce }}$ and $\mathrm{AGB}_{\text {beech. }}$. We did not consider AGB estimation for mixed plots due to small number of plots for splitting data in training and validation sets.

\section{Model 3}

The third model was generalized using metrics from both hyperspectral and LiDAR data. We used five VIs, band ${ }_{505}$ and band ${ }_{688}$ from hyperspectral image and TreeHeight ${ }_{\text {LiDAR }}$ from LiDAR data averaged for each plot. We separated model predictors by plots. The first set of predictors was for spruce plots, the second set of predictors was for beech plots and the third set of predictors was for all plots. We did not consider predictors for mixed plots due to small number of plots for splitting data in training and validation sets.

The General Regression Models module of Statistica-1.2 software was applied for model generalization. After several iterations with changing of the range of distribution, link functions and options for exploratory analyses the final linear model with Normal distribution for the response variable, log link function and standard forward stepwise selection of effects was created. Wald Test was used to verify the true values of different predictors.

\section{Statistical analysis}

Confusion matrix was calculated to compare species classification result with ground truth information. The overall accuracy was calculated by summing the number of pixels classified correctly and dividing by the total number of pixels. The Kappa coefficient (Rosenfield and Fitzpatrick-Lins 1986) was used to compare the specific class differences between the classifications. We used the coefficient of determination, $\mathrm{R}^{2}$, to indicate how well plot level AGB values from hyperspectral and LiDAR data fit the respective AGB from field data. Root mean squared error (RMSE) was calculated for quantitative assessment of AGB values from the study models. The coefficient of variation of the RMSE, CV $_{\text {RMSE, }}$, was useful for non-dimensional comparison of RMSE normalized to the mean of the observed data. 


$$
\begin{gathered}
R M S E=\sqrt{\frac{\sum_{i=1}^{n}\left(y_{i}-\widehat{y_{i}}\right)^{2}}{n},} \\
C V_{\text {RMSE }}=\frac{R M S E}{\bar{y}},
\end{gathered}
$$

where $\mathrm{n}$ is a number of observations, $\mathrm{y}_{\mathrm{i}}$ is the value estimated from field data for observation $i$, is the predicted value for observation $i$ and is the mean of the variable.

Wald Test was used to test the true values of different parameters in the Model 3.

\section{Results}

The accuracy of the classification from HS data was estimated by the confusion matrix. The overall accuracy and Kappa coefficient for the hyperspectral data classification was $87 \%$ and 0.85 , respectively. We excluded classes of "pine", "silver fir", "shadows" and "artificial objects" from a final map for biomass estimation for this study. Classes of "pine" and "silver fir" were excluded due to minor presence of these species in plots and absence of local allometry for these species. The final map for AGB estimation contained three forest cover classes: "spruce", "beech" and "mixed". After hyperspectral classification 34 spruce (a), 15 broadleaves (b) and 10 mixed (c) plots were designated (Fig. 3) for further biomass modelling.

Table 1 contains equations obtained for three AGB models for study area. Table 2 summarizes results obtained for AGB estimation based on three models using metrics from airborne LiDAR data and HS data. AGB map obtained from the third model is demonstrated (Fig. 4).

The accuracy of the LiDAR input - the canopy density metric - was estimated by a comparison with the number of trees from field data (Fig. 5). The accuracy of the LiDAR input - the canopy height model - was estimated by a comparison with the height of trees measured in field (Fig. 6).

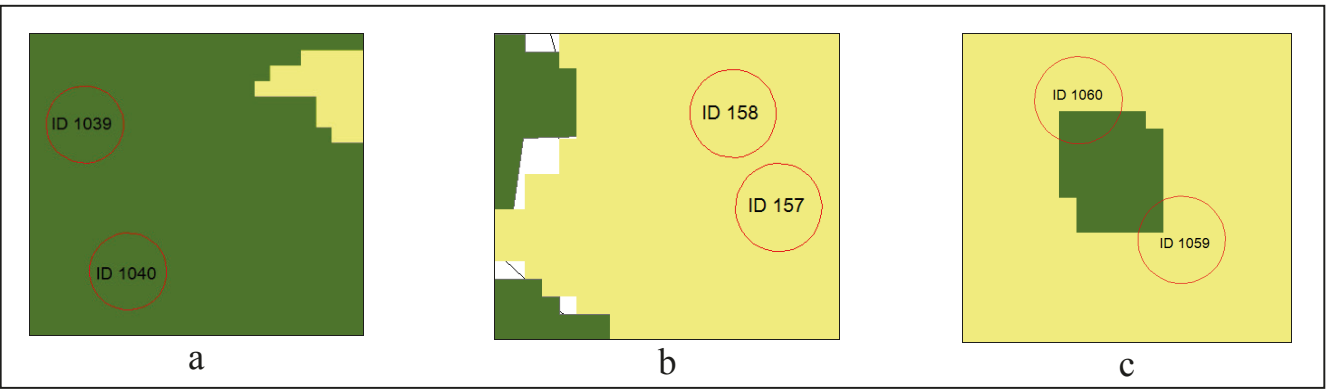

Fig. 3: Fragments of the map of species composition with tree plots (yellow color is beech, green color is spruce).

\begin{tabular}{|c|c|c|}
\hline $\mathbf{N}$ & Equation & $\mathbf{R}^{2}$ \\
\hline Model 1 & $A G B_{\text {plot }}=\left(0.007 *\right.$ CanopyDensity $\left.{ }_{\text {LiDAR }}+0.29\right) * A G B_{\text {tree }}$ & 0.7 \\
\hline Model 2 & $A G B_{p l o t}=12.8 *$ TreeHeight $t_{L i D A R}-99.9$ & 0.72 \\
\hline \multirow[t]{3}{*}{ Model 3} & $A G B_{\text {plot }}=540 * \mathrm{NDVI}_{705}+6.7 * H e i g h t_{L i D A R}-262.6$ (all) & 0.75 \\
\hline & $A G B_{\text {plot }}=294 * \mathrm{VOG} 1+7.9 * H e i g h t_{\text {LiDAR }}-425$ (spruce) & 0.78 \\
\hline & $A G B_{\text {plot }}=706 * N D V I_{705}+7.67 *$ Height $t_{L i D A R}-282$ (beech) & 0.76 \\
\hline
\end{tabular}

Tab. 1: Equations for AGB models for study area. 
Tab. 2: Results obtained for AGB estimation based on three models using metrics from LiDAR data and HS data.

\begin{tabular}{lllll}
\hline & N of predictors & $\mathbf{R}^{2}$ & $\begin{array}{c}\text { RMSE, } \\
\text { t/ha }\end{array}$ & $\begin{array}{c}\mathbf{C V}_{\text {RMSE }} \\
\text { \% }\end{array}$ \\
\hline \multicolumn{1}{c}{ Model 1 } & & & & \\
\hline all & 56 & 0.67 & 75 & 54 \\
spruce & 34 & 0.72 & 54 & 37 \\
beech & 15 & 0.76 & 29 & 24 \\
all & 56 & 0.77 & 45 & 32 \\
spruce & 34 & 0.72 & 52 & 36 \\
beech & 15 & 0.80 & 25 & 23 \\
all & 56 & 0.79 & 35 & 25 \\
spruce & 34 & 0.80 & 32 & 25 \\
beech & 15 & 0.42 & 29 & 36 \\
\hline
\end{tabular}

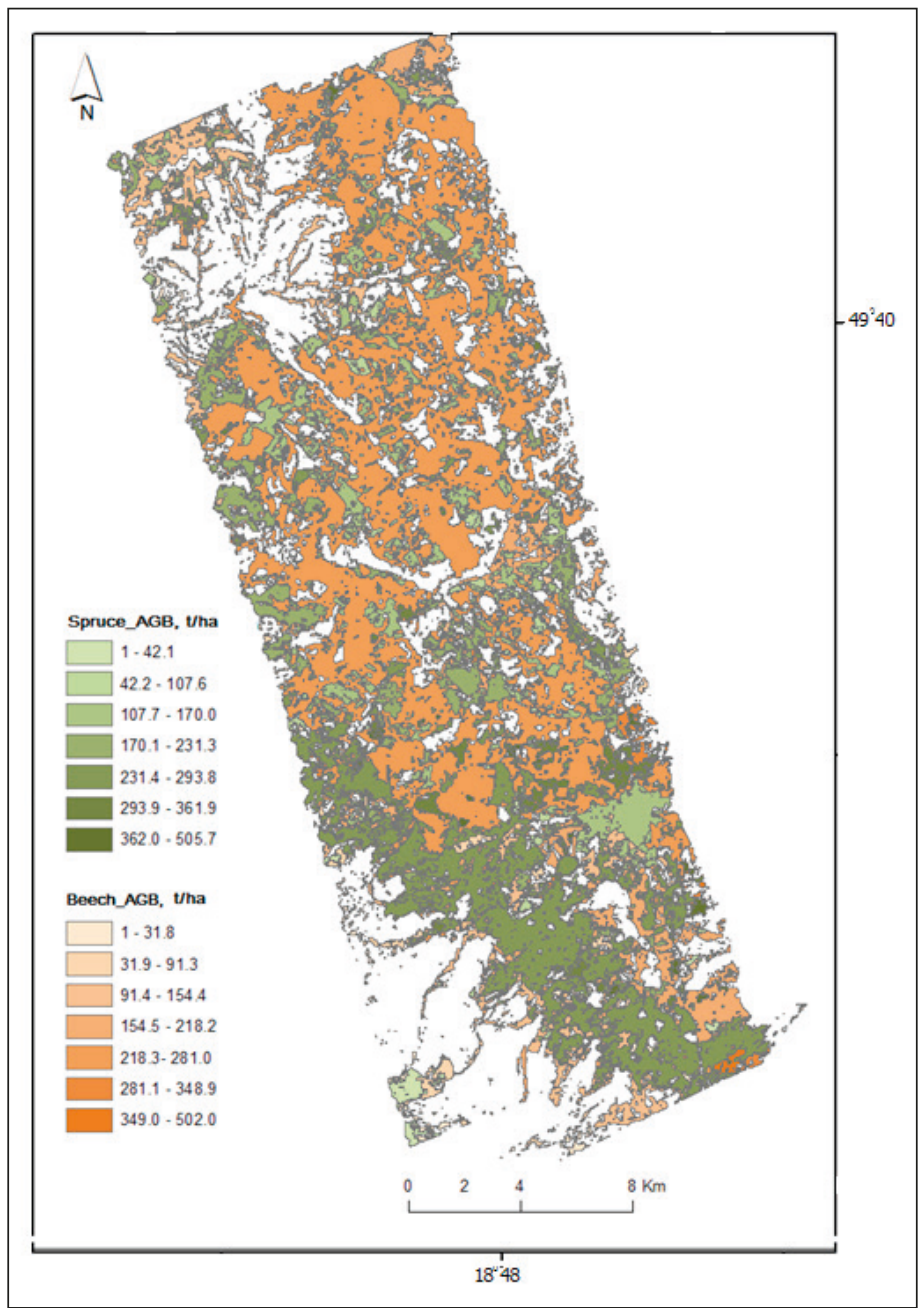

Fig. 4: Map of AGB estimation from Model 3. 


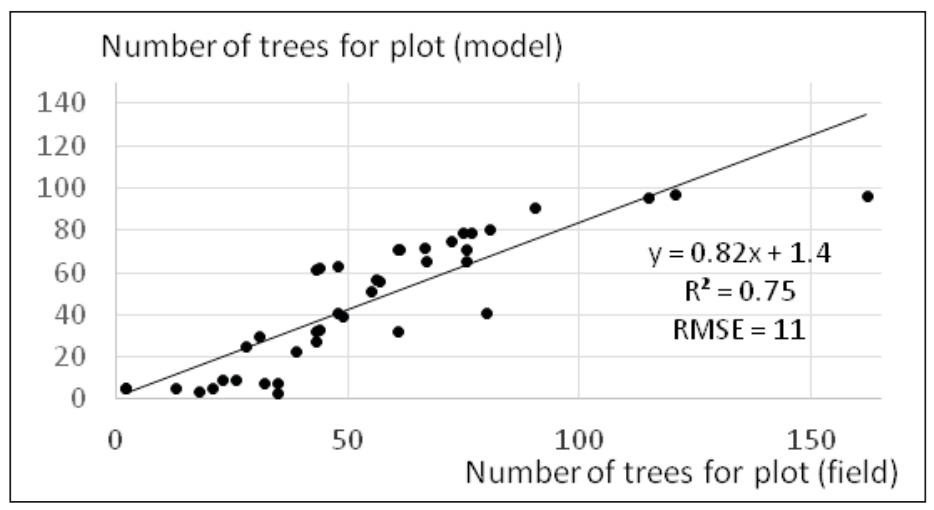

Fig. 5: Comparison between number of trees from laser scanning and number of trees from field data.

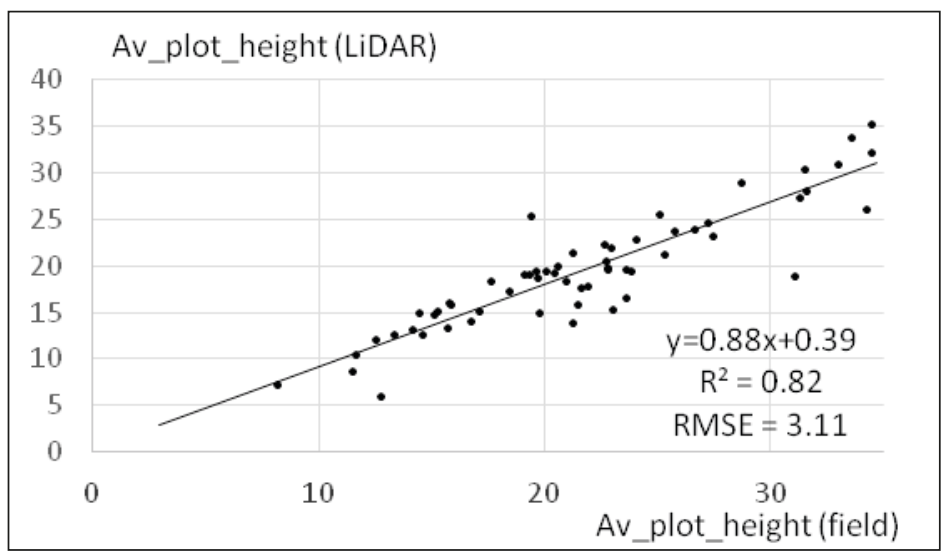

Fig. 6: Comparison between tree heights derived from laser scanning (Av_plot_height, LiDAR) data and tree heights measured in the field (Av_plot_height, field).

Results of statistical Wald Test for Model 3 is presented in Table 3.

Tab. 3: Test of all effects for Model 3.

\begin{tabular}{lccccccc}
\hline \multirow{2}{*}{ All plots } & \multicolumn{1}{c}{} & & & & & \\
\cline { 2 - 8 } & LiDAR_Height & Band_505 & Band_688 & WBI & VOGI & NDVI & NDVI $_{705}$ \\
\hline Wald Stat. & $\mathbf{2 3 . 6 9}$ & 0.01 & 0.16 & 2.90 & 2.05 & 3.16 & $\mathbf{1 7 . 1 2}$ \\
$\mathrm{p}$ & 0 & 0.82 & 0.74 & 0.06 & 0.11 & 0.11 & 0.0001 \\
\hline Spruce plots & & & & & & & \\
\hline Wald Stat. & $\mathbf{6 8 . 0 3}$ & 0.27 & 0.49 & 0.52 & $\mathbf{1 4 . 9 6}$ & 3.14 & 4.09 \\
$\mathrm{p}$ & 0 & 0.60 & 0.48 & 0.45 & 0.0001 & 0.15 & 0.20 \\
\hline Beech plots & & & & & & & \\
\hline Wald Stat. & $\mathbf{3 7 . 3 9}$ & 4.57 & 1.17 & 2.35 & 6.15 & 2.61 & $\mathbf{7 . 2 6}$ \\
$\mathrm{p}$ & 0 & 0.03 & 0.28 & 0.02 & 0.01 & 0.11 & 0.001 \\
\hline
\end{tabular}




\section{Discussion}

A map of species composition was used to derive AGB from three models using LiDAR and HS data. The classification of the hyperspectral data separated four forest classes: "spruce", "beech", "silver fir" and "pine" (overall accuracy of $87 \%$ and Kappa coefficient of 0.85). Our result confirms recent studies showing that airborne hyperspectral data can be used in species classification with high accuracy. For example, Buddenbaum et al. (2005) reported the classification accuracy (Kappa) of 0.74 in coniferous forest stands from the airborne hyperspectral data. Martin et al. (1998) achieved the overall classification accuracy of $75 \%$ with the classification of 11 forest cover types based on the airborne hyperspectral data. In comparison, species classification accuracies was $72 \%, 60 \%$, and $40 \%$ for hemlock (Tsuga heterophylla (Raf.) Sarg.), balsam (Abies balsamea), and redcedar (Thuja plicata Donn ex D. Don) trees from airborne hyperspectral scanner data of $0.7 \mathrm{~m}$ resolution (Leckie et al., 2005).

We calculated for further selection 8 predictors ( 6 from HS data and 2 from LiDAR data) that already had a similar prediction potential of AGB. The importance of prediction method for remote sensing-based estimations of forest AGB reviewed in the current study of Fassnacht et al. 2014. They indicated that it is needed for a minimum but significant number of reference samples from remote sensing data.

Nevertheless, our results of HS predictors are comparable to only some recent works. We obtained the narrowband $\mathrm{NDVI}_{705}$ and VOGl indices were optimal predictors from 6 HS predictors for AGB modelling (Table 3). It coincides to the stated finding that especially the green part of the visual domain and the NIR spectral region contain useful information correlated to the AGB modelled responses. For example, Zhang et al. (2009) showed the greenness indices might have a positive potential for prediction of the AGB. Ardo (1992) investigated the relationship between NIR band spectral radiance and the volume of Sweden coniferous forest $(\mathrm{R}=0.79)$. The findings in mixed forests of Latifi et al. (2012), Chopping et al. (2011), Zheng et al. (2004) and Laurin et al. (2014) followed above-mentioned studies.

First PCA component was not selected as a model predictor in our study. Although, a highly significant correlation between the first PCA component and AGB reached values of up to 0.815 from Lu et al. (2004). Moreover, the original HS spectral bands ( $505 \mathrm{~nm}, 688 \mathrm{~nm}$ ) were not robust features and were not selected for biomass modelling in our study. Despite the hyperspectral bands ( $518 \mathrm{~nm}, 681 \mathrm{~nm}$ ) have been reported to carry important information on forest biomass in European and tropical forests (Laurin et al. 2014, Thenkabail et al. 2004, Latifi et al. 2012).

We used all indices declared in the study LiDAR metrics (tree height and canopy density for plot level) for biomass modelling. A strong relationship $\left(\mathrm{R}^{2}=0.82\right) \mathrm{LiDAR}$ tree height with the height of trees measured in the field was obtained. We expected the result due to LiDAR ability to derive plot level tree height which is in a strong relationship with measured tree height (Nasset $1997\left(\mathrm{R}^{2}=0.91\right)$, Wulder and Seemann $2003\left(R^{2}=0.67\right)$, Kankare et al. $2013\left(R^{2}\right.$ from 0.68 to 0.76$))$. We compared canopy density for plot level from LiDAR data with an average number of trees in each plot from field measurements $\left(\mathrm{R}^{2}=0.75\right.$, RMSE $\left.=11.3\right)$. Our result confirmed the statement in a recent studies statement that the laser response to a forest canopy was also a function of canopy density (Nasset et al. 2011, Kellndorfer et al. 2010).

We did not consider HS features without LiDAR metrics for AGB model due to limited predictive power of HS bands and VI (Koch 2010, Laurin et al. 2014).

Based on LiDAR metric alone (model 2) AGB was predicted best for beech plots with a coefficient of determination $\left(\mathrm{R}^{2}\right)$ equal to 0.80 and a RMSE of $25 \mathrm{t} / \mathrm{ha}$. For spruce and all tree species AGB was predicted with $\mathrm{R}^{2}=0.72$ $(\mathrm{RMSE}=52 \mathrm{t} / \mathrm{ha})$ and $\mathrm{R}^{2}=0.77(\mathrm{RMSE}=45 \mathrm{t} / \mathrm{ha})$ correspondingly. The results are within the range of those reported in Finish broad mixed forest stands area where airborne LiDAR data was used for plot level biomass estimation (Kankare et al. 2013). They estimated AGB with $\mathrm{R}^{2}$ values of $0.68,0.72$ and 0.71 for Norway spruce, deciduous trees and all tree species correspondingly. It should be mentioned, that a number of plots was much higher in Kankare et al (2013) - 254 plots opposite 56 plots from our study. Latifi et al. (2012) achieved relative errors of $32 \%-58 \%$ for coniferous and $32 \%-45 \%$ for total plot level biomass based on LiDAR metrics only. Our relative errors values for model 2 lie in the range of $23 \%-36 \%$.

Based on both HS and LiDAR metrics (model 3) AGB was predicted best for spruce $\left(R^{2}=0.80\right.$, RMSE $=32 \mathrm{t} / \mathrm{ha})$ and all species $\left(\mathrm{R}^{2}=0.79\right.$, $\mathrm{RMSE}=35 \mathrm{t} / \mathrm{ha}$ ). For beech plots estimated results were worse with $\mathrm{R}^{2}=0.42, \mathrm{RMSE}=39 \mathrm{t} / \mathrm{ha}$. In comparison, Popescu et al. (2004) combined LiDAR and multispectral airborne data to 
estimate the plot-level AGB in deciduous and pine forests. They found the maximum $\mathrm{R}^{2}$ values for AGB of 0.32 for deciduous and 0.82 for pines with respective RMSEs of $44 \mathrm{t} / \mathrm{ha}$ and 29 t/ha. Latifi et al. (2012) achieved relative errors of $30 \%-55 \%$ for coniferous and $35 \%-45 \%$ for total plot level biomass based on both HS and LiDAR metrics. Our relative error values for the $3 \mathrm{~d}$ model lie in the range of $25 \%-36 \%$.

The addition of HS metrics to LiDAR resulted in an increase of $\mathrm{R}^{2}$ values from 0.77 (model 2) to 0.79 (model 3) for all plots and from 0.72 (model 2) to 0.80 (model 3) for spruce plots. An improvement in the results owing to the fusion of HS and LiDAR data was reported in several studies. Laurin et al. (2014) found in an increase of $\mathrm{R}^{2}$ values from 0.64 to 0.70 obtained with combination of LiDAR metrics and HS bands. Anderson et al. (2008) observed an improvement of $\mathrm{R}^{2}$ for $25 \%$ when used the integration of LiDAR and HS imagery in a northern temperate forest. Minimum improvement in AGB estimates from fused datasets reported by Latifi et al. (2012) for coniferous forest area (values of relative error is mentioned above). The combination of HS and LiDAR information did not improve results compared to the LiDAR-only method (both mean $\mathrm{R}^{2}=0.48$ ) in German pine (Pinus Silvestric) and beech (Fagus Sylvatica) forest and beech (Nothofagus oblique Oestr.) Chilean forest (Fassnacht et al. 2014).

In summary, our research shows that there is potential for improvement of AGB assessment through fusion of HS and LiDAR metrics for spruce plots and all plots with spruce and beech species together on the study area. The AGB estimation based on HS and LiDAR data could serve as an alternative or complement approach to existing inventory data acquisition programs which use systematic airborne data acquisition for forest biomass assessment in the Beskydy Mountains forests. For the future, expanding our results to a larger forest territory would further increase our understanding of AGB assessment with HS and LiDAR data for broadleaves and mixed species in the Czech Republic forest. We are convinced that the development of a robust model with HS and LiDAR information for AGB assessment that can be applied under different natural growing conditions is an unpromising task for today from a practical point of view. Therefore, modeling the separate biomass estimates for different forest types based on HS and LiDAR data is a further possible extension of our work.

\section{Acknowledgements}

This research was supported by a postdoc project in technical and economic disciplines at Mendel University in Brno (reg. no. CZ.1.07/2. 3. 00/30.0031), by the Ministry of Education, Youth and Sports of CR within the National Sustainability Program I (NPU I) (grant number LO1415) and COST project No. OCO9001.

\section{References}

Anderson, J., Plourde, L.C., Martin, M.E., Braswell, B.H., Smith, M.I., Dubayah, R.O., et al. 2008: Integrating waveform lidar with hyperspectral imagery for inventory of a northern temperate forest. Remote Sensing of Environment, 112 (4): 1856-1870.

ARdo, J. 1992: Volume quantification of coniferous forest compartments using spectral radiance recorded by Landsat Thematic Mapper. International Journal of Remote Sensing, 13(9): 1779-1786.

Buddendaum, H., Schlerf M., Hill J. 2005: Classification of coniferous tree species and age classes using hyperspectral data and geostatistical methods. International Journal of Remote Sensing, 26 (24): 5453-5465.

Chopping, M., SchaAf, C.B., Zhao, F., Wang, Z., Nolin, A.W., Moisen G.G. et al. 2011: Forest structure and aboveground biomass in the south-western United States from MODIS and MISR. Remote Sensing of Environment, 115: 2943-2953.

Dudeni, N., Debba, P., Cho, M., Mathieu, R. 2009: Spectral band discrimination for species observed from hyperspectral remote sensing. Proceedings Workshop IEEE on Hyperspectral Image and Signal Processing WHISPERS, 26-28 August, Grenoble, France.

Fassnacht, F.E., Hartig, F., Latifi, H., Berger, C., Hernandez, J., Corvalan, P., Кoch, B. 2014: Importance of sample size, data type and prediction method for remote sensing-based estimations of aboveground forest biomass. Remote Sensing of Environment, 154: 102-114.

Goetz, S.J., Prince, S.D., Small, J., Gleason, A.C.R. 2000: Interannual variability of global terrestrial primary production: Results of a model driven with satellite observations. Journal of Geographic Research, 105: 20077-20091.

GrodzKI, W. 2006: Threats to the mountain Norway spruce stands in the Carpathians from theinsect pests. Current Problems of Forest Protection in Spruce Stands under Conversion; 
Grodzki, W., Oszako, T., Eds.; IBL, Forest Research Institute (FRI): Warsaw, Poland, pp. 71-78.

Heinzel, J., Косн. B. 2011: Exploring fullwaveform LiDAR parameters for tree species classification. International Journal of Applied Earth Observation and Geoinformation, 152-160.

Huber, S., Kneubuhler, M., Psomas, A., Itten, K., ZimmermanN, N.E. 2008: Estimating foliar biochemistry from hyperspectral data in mixed forest canopy. Forest Ecology and Management, 256 (3): 491-501.

Kankare, V., Vastaranta, M., Holopainen, M., Raty, M., Yu, X., Нyyppa, J., Нyyppa, H., Alho, P., Vittala, R. 2013: Retrieval of forest aboveground biomass and stem volume with airborne scanning LiDAR. Remote Sensing, 5: 2257-2274; doi:10.3390/rs5052257

Kellndorfer, J.M., WalKer, W.S., Lspoint, E., Kirsch, K., Bishop, J., Fiske, G. 2010: Statistical fusion of LiDAR, InSAR and optical remote sensing data for forest stand height characterization: A regional-scale method based on LVIS, SRTM, Landsat ETM+, and ancillary data sets. J. Geophys. Res. 115, doi: 10.1029/2009JG000997

Косн, B. 2010: Status and future of laser scanning, synthetic aperture radar and hyperspectral remote sensing data for forest biomass assessment. ISPRS Journal of Photogrammetry and Remote Sensing, 65: 581-590.

KozAK, J. 1996: Przestrzenny model degradacji lasów Beskidu Ślaskiego. Biuletyn KPZK, 174: 511-538.

Labrecoue, S., Fournier, R.A., Luther, J.E., Piercey, D. 2006: A comparison of four methods to map biomass from Landsat-TM and inventory data in western Newfoundland. Forest Ecology and Management, 226: 129-144.

Latifi, H., Nothdurft, A., Koch, B. 2010: Nonparametric prediction and mapping of standing timber volume and biomass in a temperate forest: Application of multiple optical/LiDAR-derived predictors. Forestry, 83: 395-407.

Latifi, H., Fanssnacht, F., Косн, B. 2012: Forest structure modelling with combined airborne hyperspectral and LiDAR data. Remote Sensing of Environment, 121: 10-25.

Laurin, G.V., Chen, QI, Lindsell, J.A., Coomes, D.A., Del Frate, F., Guerriero, L., Pirotti, F., Valentini, R. 2014: Above ground biomass estimation in an African tropical forest with lidar and hyperspectral data. ISPRS Journal of Photogrammetry and Remote Sensing, 89: $49-58$.
Leckie, D.G., Gougeon, F.A., Tinis, S., Nelson, T., Burnett, C.N., Paradine, D. 2005: Automated tree recofnition in old growth conifer stands with high resolution digital imagery. Remote Sensing of Environment, 94:311-326.

Lu, D., Mausel, P., Brondizio, E., Moran, E. 2004: Relationships between forests stand parameters and Landsat TM spectral responses in the Brazilian Amazon Basin. Forest Ecology and Management, 198: 149-167.

Main-Knorn, M., Cohen, W.B., Kennedy, R.E., Grodski, W., Pflugmacher, D., Griffiths, P., Hostert, P. 2013: Monitoring coniferous forest biomass changes using a Landsat trajectory-based approach. Remote Sensing of Environment, 139: 277-290.

Main-Knorn, M., Moisen, G.G., Healey, S.P., Keeton, W.S., Freeman, E.A., Hostert, P. 2011: Evaluating the Remote Sensing and Inventory-based estimation of biomass. Remote Sensing, 3: 1427-1446.

Martin, M.E., Newman, S.D., Aber, J.D., ConGALton, R.G. 1998: Determining forest species composition using high spectral resolution remote sensing data. Remote Sensing of Environment, 65 (3): 249-254.

Michalko, J. 1986. Geobotanicka mapa CSSR. Veda, Bratislava:186 pp.

NASSET, E. 1997: Determination of mean tree height of forest stands using airborne laser scanner data. IJRS J.Photogram, 52: 49-56.

Nasset, E., Gobakken, T., Solberg, S., Gregoire, T.G., Nelson, R., Stahl, G. 2011: Model-assisted regional forest biomass estimation using LiDAR and InSAR as auxiliary data: A case study from a boreal forest area. Remote Sensing of Environment, 115: 3599-3614.

Penner, M., Power, K., Muhairwe, C., Tellier, R., WANG, Y. 1997: Canada's forest biomass resources, deriving estimates from Canada's Forestry Centre. Victoria, BC, Info. Re BC-X-370.

Popescu, S.C., Wynne, R.H., Scrivani, J.A. 2004: Fusion of small-footprint lidar and multispectral data to estimate plot-level volume and biomass in deciduous and pine forests in Virginia, USA. Forest Science, 50: 551-565.

Richards, J. A. 1999: Remote Sensing Digital Image Analysis. Springer-Verlag, Berlin, p. 240.

Rosenfield, G., Fitzpatrick-Lins, K. 1986: A coefficient of agreement as a measure of thematic classification accuracy. Photogrammetric Engineering and Remote Sensing, 52: 223-227.

Running, S.W., Thornton, P.E., Nemani, R., GLASSY, J.M. 2000: Global terrestrial gross and primary productivity from the earth observing system. In O.E. Sala, R. Jackson, 
H.A. Mooney, \& R. Hwarth (Eds.), Methods in ecosystem science, pp. 44-57. New York: Springer-Verlag.

SCHLERF, M. 2006: Determination of structural and chemical forest attributes using hyperspectral remote sensing data - case studies in Norway spruce forests. Dissertation at University of Trier, Geography/Geosciences, Germany, 203 pp.

Thenkabail, P.S., Encola, E.A., Ashton, M.S., Van Der Meer, B. 2004: Accuracy assessment of hyperspectral waveband performance for vegetation analysis applications. Remote Sensing of Environment, 90: 23-43.

Tsui, O.W., Coops, N.C., Wulder, M.A., MarShall, P.L., Mccardle, A. 2012: Using multifrequency radar and discrete-return LiDAR measurements to estimate aboveground biomass and biomass components in a coastal temperate forest. ISPRS Journal of Photogrammetry and Remote Sensing, 69: 121-133.

Vogelmann, J.E. Rock, B.N., Moss, D.M. 1993: Red edge spectral measurements from sugar maple leaves. International Journal of Remote Sensing, 14: 1563-1575.

Wirth, C., Schumacher, J., Schulze, E. - D. 2004: Generic biomass functions for Norway spruce in Central Europe - a meta-analysis approach toward prediction and uncertainty estimation. Tree Physiology, 24: 121-139.

Wulder, M.A., SeEmann, D. 2003: Forest inventory height update through the integration of lidar data with segmented Landsat imagery. Can.J.Remote Sensing, 29 (5): 536-543.

Wutzler, T., Wirth, C., Schumacher, J. 2008: Generic biomass functions for Common beech (Fagus sylvatica L.) in Central Europe - predictions and components of uncertainty. Canadian Journal of Forest Research, 38 (6): 1661-1675.

Zhang, H., Hu, H., Yao, X., Zheng, K. F. 2009: Estimation of aboveground biomass using HJ-1 hyperspectral images in Hangzhou Bay, China. International Conference on Information Engineering and Computer Science, ICIECS 2009.

Zheng, D.L., Rademacher, J., Chen, J.Q., Crow, T., Bresee, M., Le Moine, J. et. al. 2004: Estimating aboveground biomass using Landsat 7 ETM + data across a managed landscape in northern Wisconsin, USA. Remote Sensing of Environment, 93: 402-411.

Zolkos, S.G., Goetz, S.J., Dubayan, R. 2013: A meta-analysis of terrestrial aboveground biomass estimation using lidar remote sensing. Remote Sensing of Environment, 128: 289-298. 